\title{
Polarización ocupacional y racialización de la desigualdad social. Situación de los latinos frente a los cambios económicos y demográficos en Estados Unidos
}

\author{
Alejandro I. Canales* \\ Recepción: 25 de octubre de 2017 Aceptación: 30 de enero de 2018
}

Resumen Estados Unidos experimenta un proceso de transformaciones que se refieren a su estructura tanto económica como demográfica. Por un lado, la reestructuración económica en la actual fase de globalización conlleva una transformación de la matriz productiva y laboral, en donde junto con un proceso de polarización del empleo resurge con fuerza un proceso de racialización de la desigualdad y estratificación social. Por otro lado, las transformaciones de las estructuras demográficas que, según estimaciones de la Oficina del Censo, implicarían un eventual proceso de remplazo demográfico hacen que Estados Unidos transite de haber sido históricamente un país de blancos a ser una sociedad de minorías demográficas. La combinación de ambas tendencias abre un nuevo escenario no exento de conflictos y tensiones. Los nuevos equilibrios demográficos que ya se prefiguran en estados como California no parecen ser compatibles con el mantenimiento de formas racializadas de la desigualdad social y la estructura de clases.

PALABRAS CLAVE: migración internacional, racialización, polarización ocupacional, remplazo demográfico, Estados Unidos, latinos.

\section{Occupational polarization and racialization of social inequality. Latinos in economic and demographic changes in the United States}

Abstract The United States is facing a process of transformations that refer to both its economic and demographic structure. On the one hand, the economic restructuring in the current phase of globalization entails a transformation of the productive and labor matrix, where together with a process of

Profesor-investigador en el Departamento de Estudios Regionales-INESER de la Universidad de Guadalajara, acanales60@gmail.com 
employment polarization, a process of racialization of social inequality and stratification is re-emerged. On the other hand, the transformations of the demographic structures that according to estimates of the Census Bureau, would imply an eventual process of demographic replacement, make that the United States passes from having been historically a white country to being a society of demographic minorities. The combination of both tendencies opens a new scenario not free of conflicts and tensions. The new demographic balances that are already prefigured in states like California do not appear to be compatible with the maintenance of racialized forms of social inequality and class structure.

KEY WORDS: international migration, racialization, occupational polarization, demographic replacement, United States, latinos.

\section{Introducción}

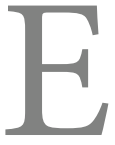

stados Unidos experimenta un ya largo periodo de transformaciones que se refieren a su estructura tanto económica como demográfica. Por un lado, las transformaciones económicas y productivas que se derivan de la actual fase de globalización económica y se manifiestan en una recomposición y polarización de la estructura ocupacional. Por otro lado, las transformaciones de las estructuras demográficas que se derivan del envejecimiento de la población nativa y la dependencia creciente de inmigración de origen latinoamericano.

La combinación de ambas tendencias abre un nuevo escenario en donde la polarización de las ocupaciones se manifiesta como un proceso de racialización de la matriz social y laboral de Estados Unidos (Bonilla Silva, 2002). Asimismo, conforman un contexto no exento de conflictos y tensiones en que la inmigración ocupa un lugar central. Por un lado, es indiscutible el rol de las migraciones en la reproducción social y económica de Estados Unidos (Canales, 2015a). Pero, por otro lado, ello entra en tensión y conflicto con la forma racializada que adopta el proceso de polarización de las ocupaciones y de la estructura de clases en la sociedad norteamericana (Maldonado, 2009). A ello se agrega un hecho no menor, que es el cambio en la estructura y composición étnica de la población, que hace que estos procesos de racialización de la desigualdad social deriven potencialmente en situaciones de alta conflictividad social y política (Camarillo \& Bonilla, 2001).

En este contexto, nos interesa analizar y describir los alcances que pueden tener estos procesos, así como sus consecuencias en términos de la situación que enfrentan los inmigrantes latinos y mexicanos en particular. Iniciamos con una descripción de los cambios económico-productivos, y su consecuencia más directa en la 
polarización de la estructura de ocupaciones. En la sección siguiente analizamos los cambios demográficos y el papel de las migraciones en el proceso de remplazo demográfico que ellos implican. A continuación analizamos las consecuencias de estos dos procesos, que se manifiestan en la racialización de la desigualdad social y de la estructura de las ocupaciones.

\section{Cambio económico-productivo en la postcrisis}

Diversos autores han documentado las nuevas formas de polarización y desigualdad social que surgen en Estados Unidos y otros países desarrollados como resultado de la globalización económica (Stiglitz, 2012; Pickety, 2015; Bauman, 2014). A ello cabe agregar los impactos de la crisis que, entre otros aspectos, implicó la profundización de ciertos procesos que ya se venían manifestando. Nos referimos, por un lado, a la relocalización de capitales y procesos productivos desde Estados Unidos hacia otras regiones del mundo, aprovechando las ventajas que ofrecen en cuanto a valor de la fuerza de trabajo, exenciones tributarias, flexibilidad en políticas ambientales, entre otros. Esto ha profundizado el proceso de desindustrialización y terciarización de la economía norteamericana, lo que transformó las bases de su actual matriz productiva.

Expresión de ello es la deslocalización de industrias manufactureras y otros procesos productivos, que ha redundado en una importante reducción de las ocupaciones y los puestos de trabajo directamente productivos (Castillo Fernández, 2016). Junto con ello, la terciarización de la economía no solo ha generado un incremento de empleos de alto nivel, sino también el auge de puestos de trabajo en servicios productivos pero de baja calificación, junto con el incremento de la ocupación en los servicios sociales y personales.

Esta nueva matriz productiva da origen a un proceso de polarización de la estructura del empleo, en donde, junto con el auge de ocupaciones de alto nivel de reflexividad y conocimiento propias de la economía de la información, se da también un importante crecimiento de puestos de trabajo altamente flexibles y desregulados que configuran nuevos contextos de precarización del empleo y de nuevas formas de vulnerabilidad de la fuerza de trabajo (Kesselman, 2010).

Asimismo, si bien la crisis económica de años recientes implicó una baja en el nivel de empleo, no alteró en lo fundamental esta base de diferenciación étnica de las ocupaciones. Por el contrario, los datos indican que la crisis ha tendido a reforzar la tendencia a la polarización del empleo, profundizando así los patrones de desigualdad y diferenciación étnica de la estructura ocupacional. 
Para ilustrar esta tesis, a continuación presentamos un análisis estadístico basado en una clasificación de las ocupaciones que nos permite medir y estimar la dimensión de la polarización del empleo y la desigualdad socioocupacional que implica. Para ello hemos reclasificado la estructura de ocupaciones con base en las siguientes grandes categorías de análisis.

Estratos altos:

Actividades de Dirección del proceso de trabajo. Este proceso incluye gerentes, ejecutivos, managers y chief executive officers (CEOs).

Profesionales. Son actividades que exigen un alto nivel de preparación y formación técnico-profesional. Se dedican al procesamiento de información y la aplicación del conocimiento al proceso de trabajo.

Estratos medios:

Actividades de administración y distribución. Se refiere a actividades de apoyo a la dirección, así como a la distribución y comercialización de los bienes y servicios producidos. Corresponde a empleados y trabajadores de cuello blanco en general.

Actividades de producción. Trabajos vinculados directamente al procesamiento y la transformación de bienes y mercancías.

Estratos bajos:

Jornaleros y obreros de la construcción. Es una actividad altamente volátil y que es muy sensible a la dinámica del ciclo económico.

Actividades de reproducción social. Corresponden a trabajos y servicios que se vinculan directamente con la reproducción de la población, tales como el servicio doméstico, industria del cuidado y atención de personas (de adultos mayores, enfermos y niños), preparación de alimentos, limpieza y mantenimiento, entre muchas otras.

Entre el año 2000 y el 2017 el empleo en Estados Unidos se incrementó en 16.1 millones de puestos de trabajo, cifra que representa un $12 \%$ acumulado en todo el periodo. Sin embargo, este crecimiento no se reprodujo por igual en todas las ocupaciones, sino que se dio en una forma muy diferenciada, lo que contribuye a profundizar la polarización socioocupacional. Mientras que los trabajos ubicados en los extremos de la jerarquía ocupacional son los más dinámicos y de mayor crecimiento, los ubicados en los niveles medios se han estancado y deprimido, e incluso con decrecimiento absoluto de los niveles de empleo.

Por un lado, en la cima de la estructura ocupacional los puestos de dirección se incrementaron en 5.3 millones, cifra que representa un crecimiento del $26 \%$ acumulado. Asimismo, los trabajos de profesionales, técnicos y científicos crecen en casi 11 millones en términos netos, cifra que representa una tasa acumulada de casi 
el 43 \% para todo el periodo. En este caso se trata de dos tipos de trabajos. Por un lado, profesionales y técnicos que prestan sus servicios a empresas en los procesos de investigación y desarrollo, innovación y aplicación de nuevas tecnologías, así como en la gestión empresarial y administración (managment) de las empresas (organización, planificación, dirección y control del proceso de trabajo), y por otro lado, profesionales en los servicios sociales, educación, salud y diversos servicios públicos que ofrecen tanto el Estado como el sector privado, y que se orientan más bien a la atención de la población.

En el extremo opuesto de la jerarquía ocupacional, también se da un importante crecimiento en especial de las ocupaciones dedicadas a la reproducción cotidiana de la población de los estratos medios y altos. Entre el año 2000 y el 2017 el empleo en estos servicios personales de todo tipo creció en 8.1 millones de nuevos puestos de trabajo, cifra que representa un crecimiento de casi el $50 \%$ del empleo en estas ocupaciones, lo que las sitúa como las de mayor dinamismo relativo en todo el

GRÁFICA 1. Estados Unidos, 2000-2017. Crecimiento del empleo según grandes estratos ocupacionales

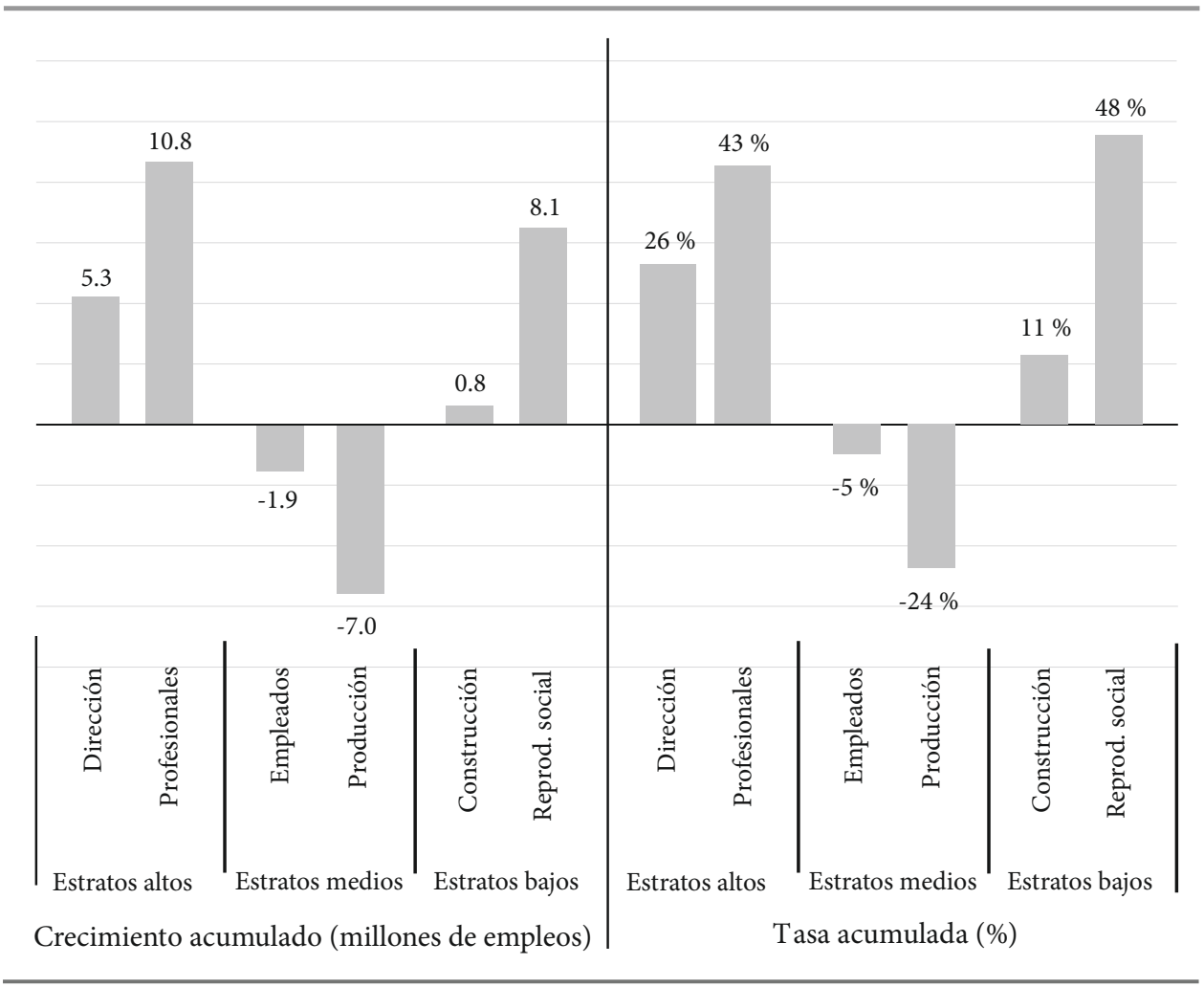

Fuente: Current Population Survey, March supplement 2000 y 2017. 
periodo. Se trata de un crecimiento relevante tanto por su magnitud absoluta y relativa como por su función en la estructura social y de la reproducción de la desigualdad social. El incremento de la población ocupada con altos niveles de ingreso, recursos y poder adquisitivo ha derivado en una promoción de la demanda de servicios personales tanto altamente calificados (diseñadores de interiores, psicoanalistas, boutiques de exclusividad, etc.) como de baja calificación (servicio doméstico, servicios de limpieza y mantenimiento, preparación de alimentos y servicios del hogar y la vivienda, industria del cuidado, entre muchos otros).

Por el contrario, las ocupaciones en los niveles medios, tanto en servicios de administración (empleados y oficinistas, secretarias, vendedores y similares) como en actividades de producción directa (obreros y trabajadores manuales de todo tipo), se reducen en volúmenes absolutos y relativos. Los primeros sufren una caída de 1.9 millones de empleos, cifra que representa una pérdida del $5 \%$ de los puestos de trabajo. En el caso de los trabajos productivos la pérdida es aún mayor, pues alcanzó los 7.0 millones de puestos de trabajo, cifra que representa la pérdida de casi el $24 \%$ de los puestos de trabajo existentes hasta el año 2000. Se trata de una pérdida muy importante directamente vinculada tanto con el impacto negativo de la crisis económica como con los procesos de deslocalización de plantas productivas de la industria manufacturera hacia otros países como estrategia de las empresas norteamericanas para enfrentar con mejores opciones la competencia de otras potencias económicas en los mercados globales.

El efecto directo de estas tendencias es la creciente polarización de la estructura socioocupacional de Estados Unidos, proceso de gran importancia pues refiere a la reducción absoluta y relativa de los trabajadores de clases medias y el incremento, en contrapartida, de los trabajadores ubicados en los extremos de la jerarquía laboral. Para medir la tendencia e intensidad de este proceso de polarización usamos como índice de polarización (IP) el cociente entre el volumen de trabajadores ocupados en los extremos altos y bajos de la pirámide ocupacional, y el volumen de trabajadores ocupados en los estratos medios de esa jerarquía laboral. En nuestro caso lo estimamos a partir de la siguiente fórmula:

Donde:

$$
I P=\frac{\text { TDIR }+ \text { TPRFS }+ \text { TREPSOC }}{\text { TADM }+ \text { TPROD }+ \text { TCONST }}
$$

IP es el índice de polarización de las ocupaciones.

TDIR representa a los trabajadores en puestos de dirección.

TPRFS representa a los trabajadores en puestos profesionales y técnicos.

TREPSOC representa a los trabajadores en puestos de reproducción social.

TADM representa a los empleados administrativos, oficinistas, y similares. 
TPROD representa a los obreros, trabajadores manuales y similares.

TCONS representa a los obreros de la construcción, jornaleros y oficios.

Al respecto, los datos son elocuentes. Como se observa en la gráfica 2, el índice de polarización ocupacional pasó de 0.78 en 1996 a 1.02 en 2005, y a 1.31 en 2017. Es decir, hoy en día, y desde hace unos 12 años, hay más trabajadores en los extremos de la jerarquía laboral que en los estratos medios, lo cual evidencia la gran pérdida de puestos de trabajo que han experimentado las clases medias en este país. Este aumento de la polarización se da por el incremento combinado y conjunto de los trabajadores ubicados en ambos extremos de la estructura ocupacional. Esto indicaría que, de ser un país con una amplia clase media, Estados Unidos se está transformando en una sociedad polarizada con una creciente desigualdad social y ocupacional, misma que como vemos es resultado de las nuevas formas que asume la matriz económico-productiva en esta fase de postcrisis de la globalización económica.

GRÁFICA 2. Estados Unidos, 1996-2017. Índice de polarización de las ocupaciones

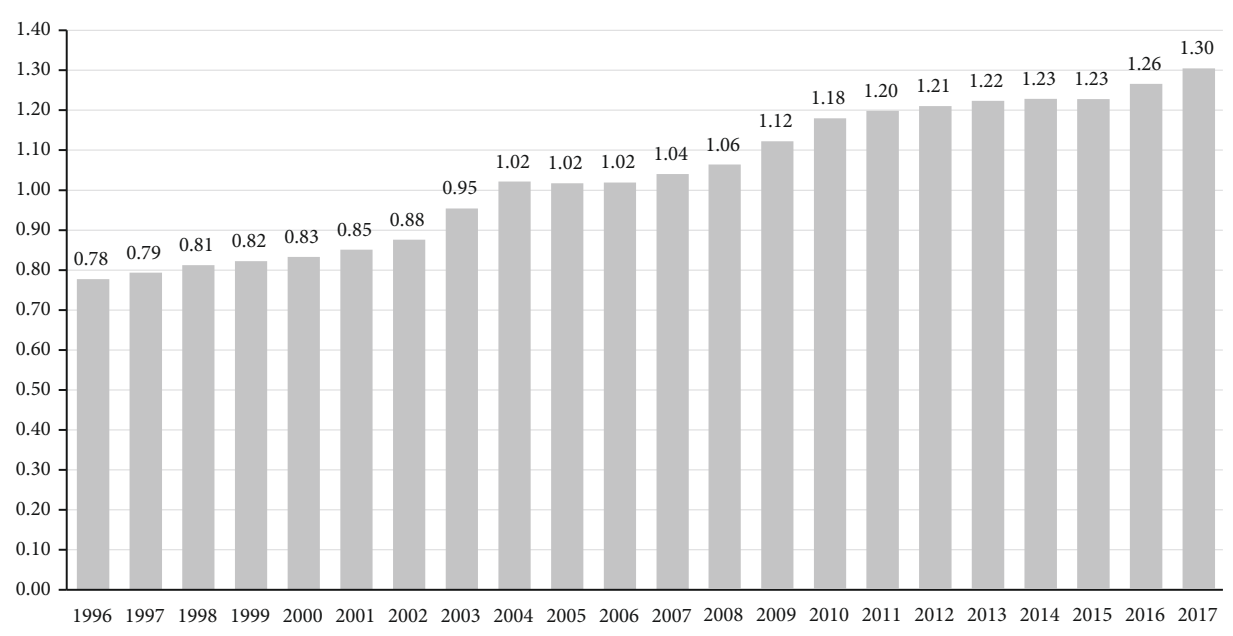

Fuentes: Estimaciones propias con base en Current population Survey, March supplement de 1995 a 2017.

Esta polarización de la estructura socioocupacional no es un asunto menor, sino de gran trascendencia social y política. Esta polarización que caracteriza a la actual matriz ocupacional de Estados Unidos es, a nuestro entender, la base de la nueva forma que adopta la desigualdad social, en la que el empleo y el trabajo dejan de ser dispositivos de cohesión e integración social, para derivar en un mecanismo 
desde el cual se configura actualmente la diferenciación y segregación social de los grupos demográficos.

No se trata solo del auge del nivel de riesgo laboral, ni de meras formas de flexibilidad y precarización del empleo y el trabajo, sino que junto con ello, y con base en esos mismos procesos, se consolida una nueva forma de estratificación social, esto es, de estructuración de las clases sociales, así como de la no articulación e integración entre ellas y la ausencia de mecanismos que impulsen la movilidad social. A diferencia de épocas anteriores, en donde el trabajo funcionaba como un mecanismo de incorporación de los sujetos a la estructura social, y que daba origen a procesos de integración y movilidad social, hoy en día el trabajo ha perdido ese rol aglutinador y de cohesión social para convertirse, en cambio, en su opuesto, en un dispositivo que consagra la desigualdad, segregación y separación de las clases, dificultando así toda opción de movilidad social y de integración de las clases en un mismo entramado social, político y económico.

Esta forma polarizada que adopta actualmente la matriz socioocupacional resulta muy pertinente cuando analizamos los patrones de inserción laboral de los trabajadores según su condición étnico-migratoria, y en el marco de los cambios demográficos que están transformando la estructura étnico-migratoria de la población norteamericana. Como veremos, no se trata solo de un proceso de polarización ocupacional, sino de nuevas formas de racialización de la desigualdad social y económica.

\section{Cambio demográfico, migraciones y remplazo demográfico}

Desde hace unas tres décadas ha experimentado y durante todo este siglo experimentará Estados Unidos un proceso de transición que lo llevará de la tradicional estructura demográfica basada en un indiscutido predominio de la mayoría blanca a una estructura paritaria en que los blancos dejarán de ser una mayoría absoluta y compartirán su posición de primacía con la población latina. Se trata de un proceso de remplazo demográfico que se sustenta en dos grandes tendencias: 1) el declive de la población blanca, producto de su envejecimiento y baja natalidad (Ortman, Velkoff, \& Hogan. 2014), y 2) el auge y crecimiento de los latinos, producto de la inmigración y de sus mayores niveles de natalidad (Canales, 2015b).

La conjunción de estos procesos, el declive de la población blanca y el crecimiento de la población latina, son la base de los cambios en la composición étnica que experimenta actualmente la población de Estados Unidos, que según estimaciones de la Oficina del Censo implicarían un eventual proceso de remplazo étnico y 
demográfico, haciendo que Estados Unidos transite de haber sido históricamente un país de blancos a ser una sociedad de minorías demográficas (Massey, 2015).

No somos los primeros en hablar en términos de un proceso de remplazo demográfico para referirnos a las consecuencias de la inmigración en contextos de muy baja natalidad y envejecimiento de las poblaciones. En un informe del 2001, la Organización de las Naciones Unidas utilizó el concepto migraciones de remplazo, la cual definía como:

... la migración internacional que se necesitaría para compensar las disminuciones en el tamaño de la población total y las disminuciones en la población en edad de trabajar, así como para compensar el envejecimiento general de una población(United Nations, 2001, p.7).

Asimismo, Coleman (2006) conceptualiza este mismo fenómeno como la tercera transición demográfica, y lo documenta para el caso de los países europeos más desarrollados. Este autor señala que de mantenerse las actuales tendencias migratorias y demográficas, hacia el año 2050 los inmigrantes representarían el 36\% de la población en Inglaterra y Gales, el 33 \% en Estados Unidos, el $29 \%$ en Holanda e Italia y el $24 \%$ en Alemania.

En ambos casos ponen su atención en el eventual remplazo demográfico de población nativa por inmigrantes en contextos donde la baja fecundidad y un alto grado de avance del envejecimiento no permiten asegurar la reproducción demográfica de las poblaciones nativas, y con ello la provisión de los contingentes necesarios de mano de obra para sustentar sus economías. En ambos casos el foco está puesto no tanto en la dinámica y las características de la inmigración como en el contexto de declive demográfico que caracteriza a los países desarrollados, principales destinos de la migración internacional contemporánea.

Desde su conformación como país independiente a fines del siglo XVIII hasta fines de la década de los setenta del siglo pasado, Estados Unidos fue siempre un país de mayoría blanca, grupo étnico que representó en todo momento más del $80 \%$ de la población; alcanzó su punto máximo hacia los años veinte del siglo pasado, cuando representó casi el 90 \% de la población. Sin embargo, a partir de 1980 la población blanca de Estados Unidos experimenta un proceso de declive demográfico que ha llevado a que ya actualmente ellos solo representen el $61 \%$ de la población y que hará que en el año 2044, por primera vez en la historia de Estados Unidos, los blancos dejen de ser una mayoría absoluta y representen solo el $49.9 \%$ de la población, para reducirse a menos del $44 \%$ en 2060 , proporción que como todo indica continuará descendiendo en las siguientes décadas.

Por su parte, las minorías étnicas fueron desde siempre minorías demográficas, que en el mejor de los casos representaron no más del $20 \%$ de la población total. Sin 


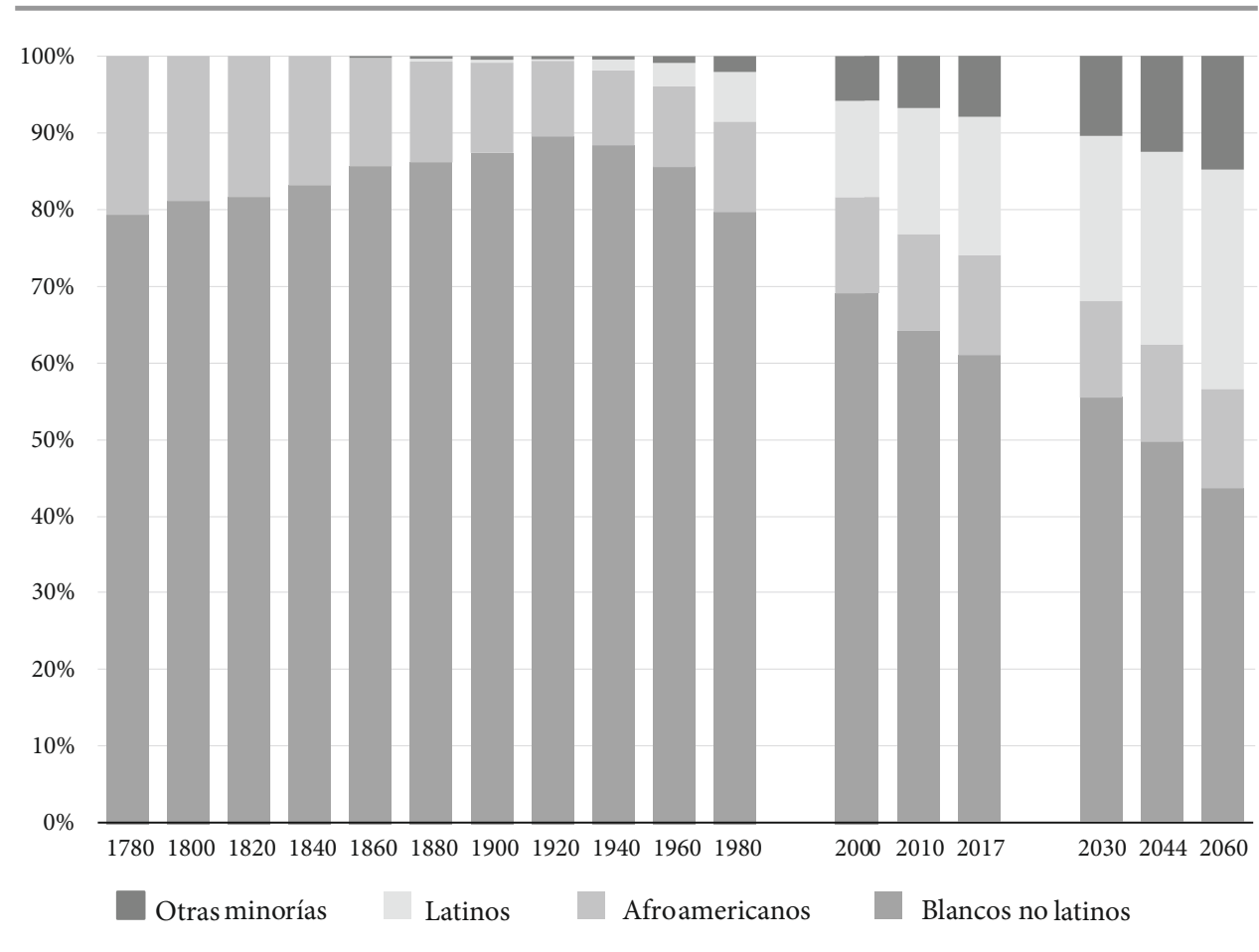

Fuentes: De 1780 a 1870: US Bureau of the Census, 1975; de 1880 a 2010: US Population Census; 2017: Current Population Survey, ASEC 2017; De 2030 a 2060, Census Bureau 2014, National Population Projections.

embargo, a partir de 1980 inicia un proceso de cambio que ha llevado a que hoy en día representen el 39\% de la población total, y se estima que en 2060 alcancen al 56 \% de la misma. Es decir, en tan solo unas décadas más, las minorías serán mayoría. Entre estas minorías destacan los latinos, quienes pasaron de ser menos del $5 \%$ de la población total en 1970 a representar el $18 \%$ en 2017; se estima que lleguen a ser el 30 $\%$ en el 2060, proporción que continuaría incrementándose en las siguientes décadas de este siglo.

Esta situación, impensable hasta hace unas décadas, es ya una realidad que se experimenta en varios estados de la Unión Americana. En California, por ejemplo, en los años setenta del siglo pasado la población blanca mantenía su posición de mayoría demográfica, pues representaba más del $70 \%$ del total. Hoy en día, sin embargo, esta situación se ha invertido. De acuerdo con los datos más recientes de la Encuesta Continua de Población (CPS, por sus siglas en inglés) de marzo de 2017, los 
blancos no solo han dejado de ser la mayoría demográfica — representan solo el $38 \%$ del total—, sino que ya han sido superados por la población de origen latino, que representa el $39 \%$ de la población total. En este sentido, la situación actual de California prefigura el futuro demográfico que se prevé para toda la Unión Americana (Chávez, 2013).

El proceso de remplazo demográfico que aquí hemos documentado ya forma parte estructural de la dinámica de la población de Estados Unidos, y lo podemos ver reflejado en la composición étnica de la estructura etaria de la población. En este sentido, la composición étnica de las pirámides de edades nos ayuda a ilustrar dos características básicas de este proceso: 1) la magnitud del remplazo demográfico, y 2) la irreversibilidad del mismo proceso, al menos en el mediano plazo, esto es, en las próximas cuatro o cinco décadas.

Las pirámides de edades nos muestran cuánto de este proceso ya ha modificado la composición étnica de la población joven e infantil, y cómo con el paso de los años este proceso se extenderá al resto de los estratos etarios, afectando así a toda la pirámide demográfica de Estados Unidos.

Como era de esperarse, hasta 1980 la población blanca constituía la mayoría demográfica en prácticamente todos los estratos de edad, y pasó del $72 \%$ en los

GRÁFICA 4.California, 1900-2017. Población según principales gruposétnicos (\%)

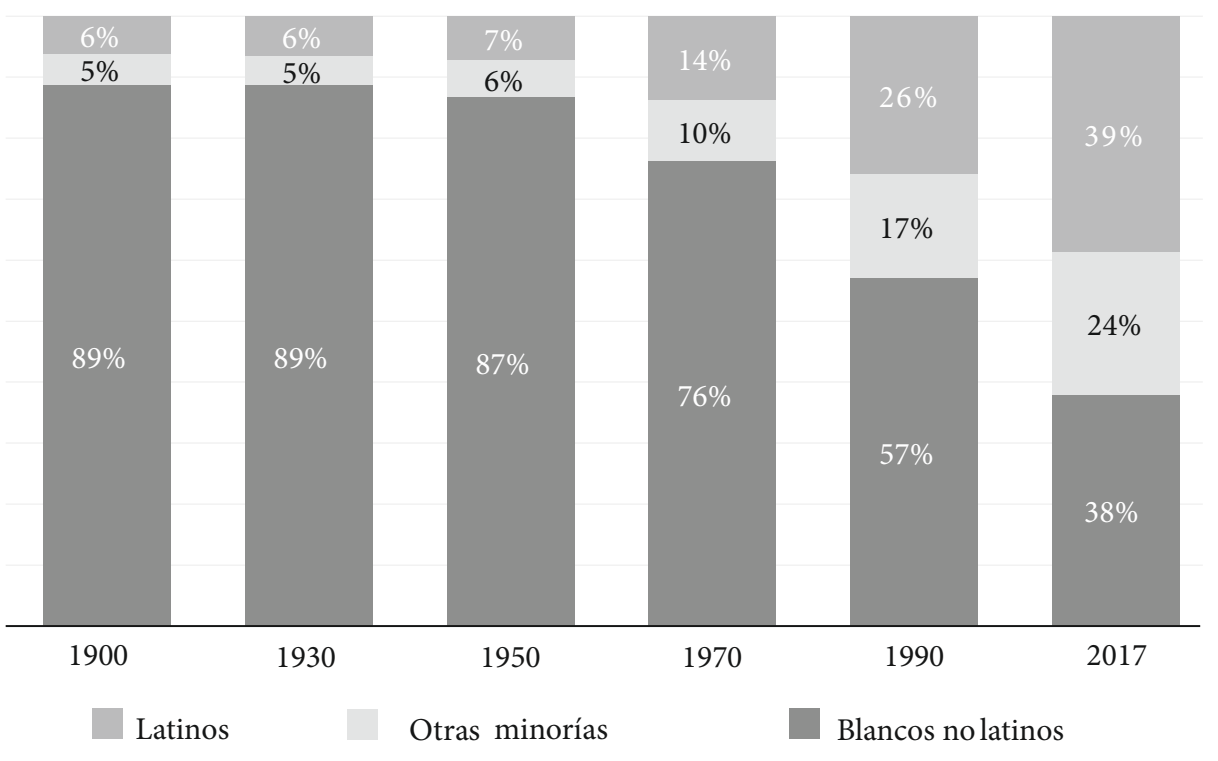

Fuentes: 1900 a 1990, US Population Census; 2017, Current Population Survey, ASEC 2017. 
menores de 10 años y al $91 \%$ en los mayores de 80 . Hacia 2015, sin embargo, ya se manifiestan cambios relevantes que prefiguran la magnitud del cambio que vendrá en las siguientes décadas. Si bien en los adultos mayores de 60 años los blancos mantienen su indiscutible primacía, pues representan más del $80 \%$ de la población en esas edades, no sucede lo mismo en los estratos más jóvenes.

En el caso de los jóvenes (de 15 a 29 años), aunque permanece el predominio de los blancos, este se reduce significativamente. En 1980 el $78 \%$ de los habitantes en estas edades era parte de la mayoría blanca. Para 2015, en cambio, solo el $55 \%$ de los jóvenes son de origen blanco, y se acerca a una relación más equilibrada entre la población joven blanca y la de las minorías étnicas.

En el caso de los niños y adolescentes menores de 15 años esta reducción es aún más significativa. En 1980 el 75 \% de los menores de 15 años era de origen blanco, relación que ya en 2015 se vuelve prácticamente paritaria, pues los blancos son solo el $51 \%$ de la población infantil y adolescente.

En ambos casos se trata de un fenómeno de mucha trascendencia, pues más allá del lugar común de que los niños y jóvenes son el futuro de toda sociedad, es evidente que la composición étnica que hoy prevalece entre la población infantil y juvenil será la que predomine en las siguientes décadas en toda la población. Por lo mismo, el cambio en la composición étnica que ya hoy experimenta la población infantil y juvenil prefigura la magnitud del cambio demográfico y el remplazo étnico que experimentará toda la población norteamericana en las siguientes décadas.

En efecto, como ilustran las proyecciones demográficas de la Oficina del Censo de Estados Unidos, se estima que para el año 2060 la actual primacía blanca se verá

GRÁFICA 5. Estados Unidos, 1980-2060. Pirámide de edades de población blanca y minorías étnicas

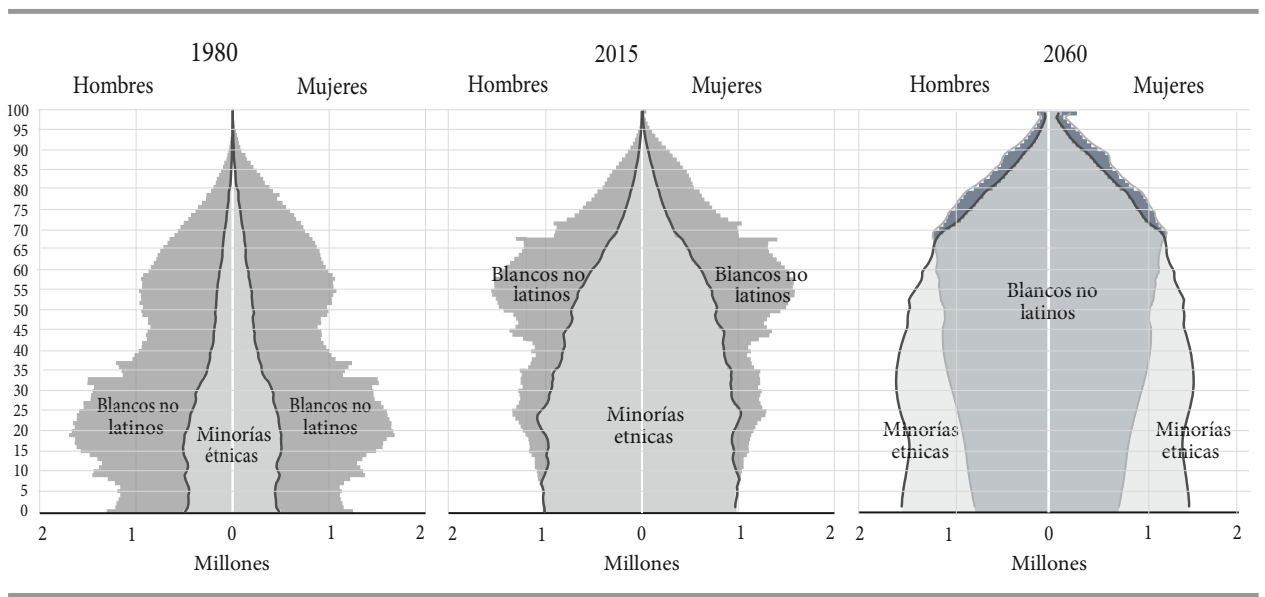

Fuentes: Elaboración propia con base en US Census Bureau 1980; American Community Survey 2015; Us Census Bureau (2014). 
restringida solo a la población adulta mayor (mayores de 65 años), pero incluso en estas edades su primacía se verá seriamente mermada. Solo el $55 \%$ de la población adulta mayor será de origen blanco, mientras que el $45 \%$ restante pertenecerá a las distintas minorías. En los demás estratos etarios los blancos serán franca minoría, pues representarán solo el $43 \%$ de los adultos jóvenes (30 a 64 años), únicamente el $38 \%$ de los jóvenes (15 a 29 años) y menos del $36 \%$ de los niños y adolescentes menores de 15 años. Estos mismos datos sobre la composición étnica de la población menor de 30 años nos indican que el remplazo demográfico continuará y se acentuará aún más después del 2060, cuando ya los últimos grupos de mayoría blanca se vayan retirando de la pirámide de edades de la población.

Nuevamente, el caso de California resulta ilustrativo de la magnitud del cambio en la composición étnica de la pirámide demográfica al que hacemos referencia. Como hemos señalado, blancos y latinos prácticamente comparten la misma proporción de la población de este estado. Sin embargo, su distribución por edades es completamente opuesta. Mientras que los blancos tienden a concentrarse en los estratos altos de la pirámide de edades, los latinos se concentran en los estratos de edades de población joven e infantil. El punto de quiebre es la edad de 45 años, a partir de ella los blancos mantienen su primacía demográfica, pero por debajo de esa edad son los latinos los que conforman el principal grupo étnico de la población. En el caso de las otras minorías étnicas, se mantienen como minorías demográficas en todos los estratos etarios.

Lo relevante, en todo caso, es que los blancos solo son mayoría en los grupos de mayor edad, esto es, los que ya van de salida de la estructura poblacional. Por lo mismo, esta forma diferenciada de la pirámide poblacional de blancos y latinos prefigura que en un futuro próximo estos últimos se conviertan en la primera minoría demográfica en prácticamente todos los grupos etarios, relegando a la población blanca al segundo lugar. Estos datos ilustran que estamos en presencia ya no solo de un cambio demográfico, sino de un verdadero remplazo étnico, el cual se expandiría a todo Estados Unidos en las siguientes décadas, tal como ya ha ocurrido en California en las últimas cuatro. La situación actual de California no es sino una prefiguración de las dimensiones que alcanzará el futuro demográfico que se prevé para toda la Unión Americana (Hayes Bautista, 2017).

En síntesis, el cambio demográfico del que aquí hablamos no es una apuesta a un futuro posible, sino un hecho real, un proceso social y demográfico que ya se ha puesto en marcha y cuyo desenlace se manifestará irreversiblemente en las siguientes décadas. Por lo mismo, ya no es suficiente con imponer políticas restrictivas a la inmigración para intentar controlar o revertir este proceso, pues el cambio demográfico ya está incubado y gestándose en la población que actualmente reside en 


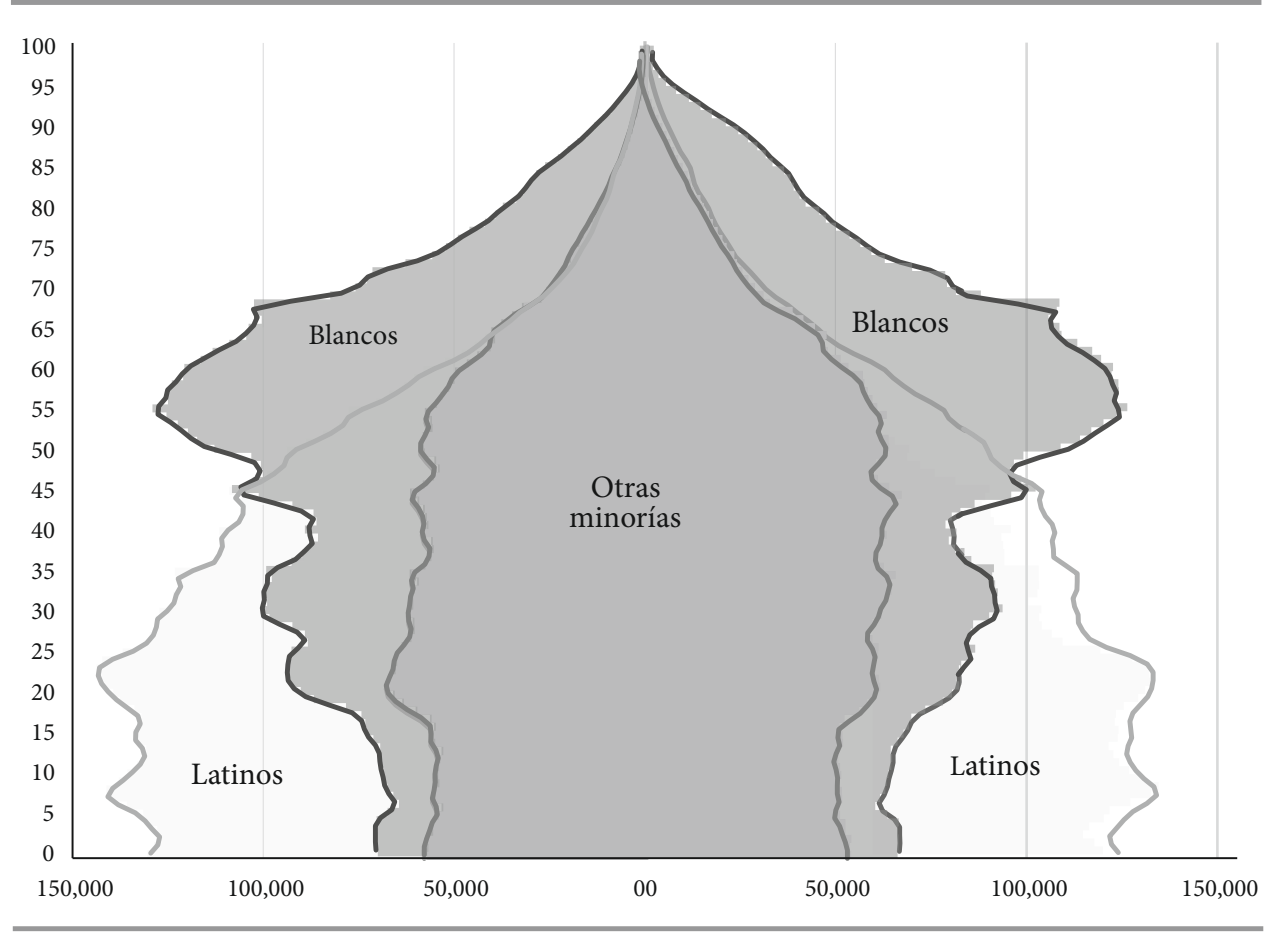

Fuentes: American Community Survey, 2015.

Estados Unidos. Frente a ello no hay muros que puedan contener ni detener este cambio demográfico, pues uno de sus actores principales es precisamente la misma población blanca, que desde hace algunas décadas experimenta un declive demográfico producto de su baja natalidad y envejecimiento progresivo.

Todos los datos hasta aquí presentados apuntan a una tesis simple pero de gran trascendencia y cuyas consecuencias son hasta ahora insospechadas. Estados Unidos dejará de ser un país de blancos, para convertirse en una sociedad de minorías demográficas. Esta composición étnica que ya está emergiendo en la Unión Americana, y que ya es una realidad en estados como California, Texas, Nuevo México, Nevada o Florida, se sustenta en la coexistencia en volúmenes más o menos paritarios de dos grandes grupos étnicos: los blancos y los latinos. Juntos, estos dos grupos étnicos representarían en un futuro próximo casi el $75 \%$ de la población total, es decir, prácticamente el mismo estatus demográfico que hace tan solo un par de décadas estaba reservado exclusivamente para la población blanca. 


\section{Centralidad de las migraciones en la dinámica económico-productiva}

El declive de la población nativa en Estados Unidos plantea una situación caracterizada por un continuo desequilibrio demográfico en el que coexisten importantes vacíos y déficits de población en edades jóvenes y activas, junto con un incremento sustancial y continuo de población adulta mayor. Estos desequilibrios demográficos se manifiestan en la generación de un déficit crónico de fuerza de trabajo, el cual surge como resultado del desajuste estructural entre las limitadas posibilidades de crecimiento de la población activa que puede proveer la dinámica demográfica y el envejecimiento de la población, por un lado, y la creciente demanda y necesidad de mano de obra que impone la dinámica de crecimiento económico y desarrollo de las fuerzas productivas, por el otro lado.

En este contexto, si Estados Unidos no contara con la presencia de inmigración mexicana, y latinoamericana en general, enfrentaría un déficit crónico de fuerza de trabajo que afectaría directamente su posición hegemónica como primera potencia política, militar y económica a nivel mundial. En términos empíricos, este déficit de mano de obra lo podemos calcular como la diferencia entre el volumen de puestos de trabajo que genera anualmente la economía y el volumen de la población económicamente activa nativa que genera la dinámica demográfica, esto es, los ocupados y desocupados nativos de ese país, sin incluir a los inmigrantes.

Considerando lo anterior, vemos que el declive demográfico que experimenta la población blanca hace que su dinámica demográfica ya no sea capaz de generar el volumen de trabajadores que demanda el crecimiento económico, como sí lo hiciera en décadas anteriores. Entre 2000 y 2017 el crecimiento económico generó un volumen de 18 millones de nuevos puestos de trabajo, cifra que representó un crecimiento de más del $13 \%$ del empleo en ese periodo, incluyendo la gran pérdida de empleos que provocó la crisis de 2008.

Sin embargo, la baja natalidad y el envejecimiento de la población blanca provocaron una reducción de su población activa en 1.7 millones de personas. Esto generó un déficit de casi 20 millones de trabajadores, el cual debió ser cubierto por las diferentes minorías étnicas. En este punto destaca el papel de la población latina; el crecimiento demográfico y la composición mayoritariamente joven de esta población le permitieron cubrir el $52 \%$ de este déficit crónico de mano de obra. El resto ha sido cubierto en partes más o menos iguales por las minorías nativas (afroamericanos, aborígenes americanos, entre otros) y por inmigrantes de otros países del mundo.

Esta contribución de los latinos y otras minorías a cubrir el déficit de fuerza de trabajo se refleja también en su aporte al crecimiento económico y al producto 
GRÁFICA 7. Estados Unidos, 2000-2017. Estimaciones del déficit de fuerza de trabajo, y cobertura del déficit según origen étnico-migratorio de la fuerza de trabajo

18.0

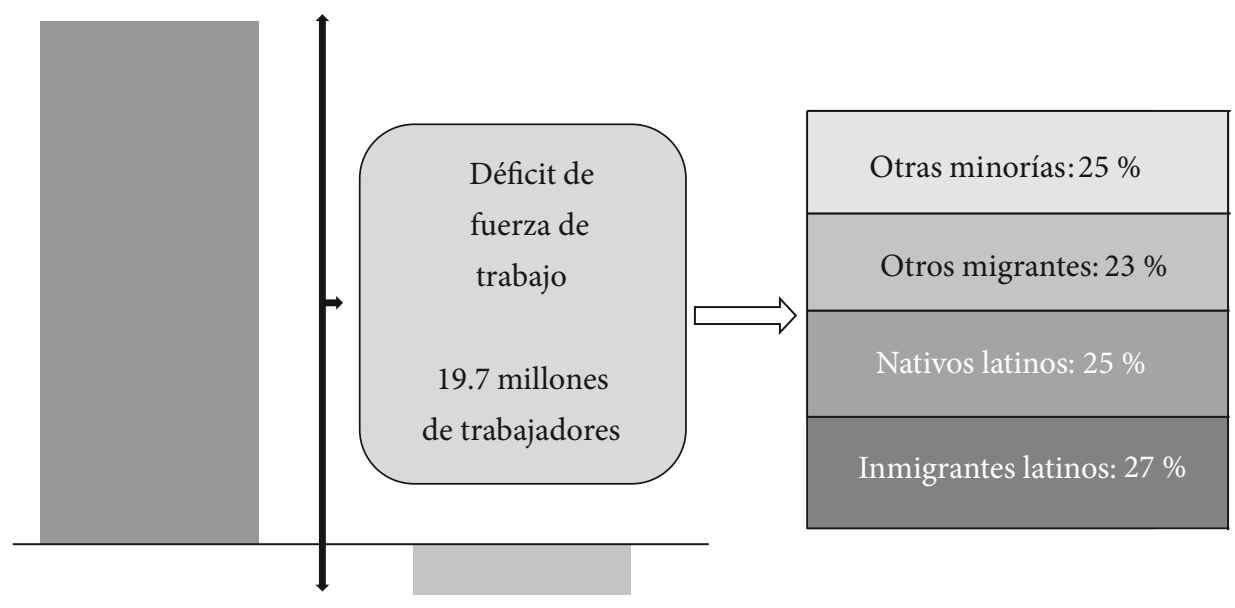

$-1.7$

Crecimiento Crecimiento PEA

Ocupaciones Blancos no latinos

Fuentes: American Community Survey, 2015.

interno bruto (PIB) de Estados Unidos. Entre 2000 y 2016 su PIB creció en 30 \%, aproximadamente. Sin embargo, los trabajadores blancos solo aportaron el $39 \%$ de este crecimiento económico, mientras que el $61 \%$ restante fue aportado por el conjunto de minorías étnicas y demográficas. Entre ellas destacan una vez más los latinos, quienes por sí solos aportaron el $28 \%$ del crecimiento del PIB, mientras que el resto se distribuye entre los inmigrantes de otros países (16\%) y las demás minorías étnicas (17\%).

Estos datos nos ilustran el grado de dependencia de la dinámica económica de Estados Unidos respecto a la participación laboral de las minorías étnicas, y en particular de la población de origen latino. O lo que es lo mismo, el grado de riesgo y vulnerabilidad a la que está expuesta la economía norteamericana debido al declive demográfico que ya experimenta la población blanca. En este sentido, el crecimiento demográfico de los latinos, y de otras minorías étnicas, resulta un recurso fundamental de que dispone la economía norteamericana para mantener la generación de los excedentes económicos necesarios para sustentar su posición hegemónica como potencia política, militar y económica a nivel global. 
GRÁFICA 8. Estados Unidos, 2000-2016. Composición del crecimiento del PIB según origen étnicomigratorio de la fuerza de trabajo
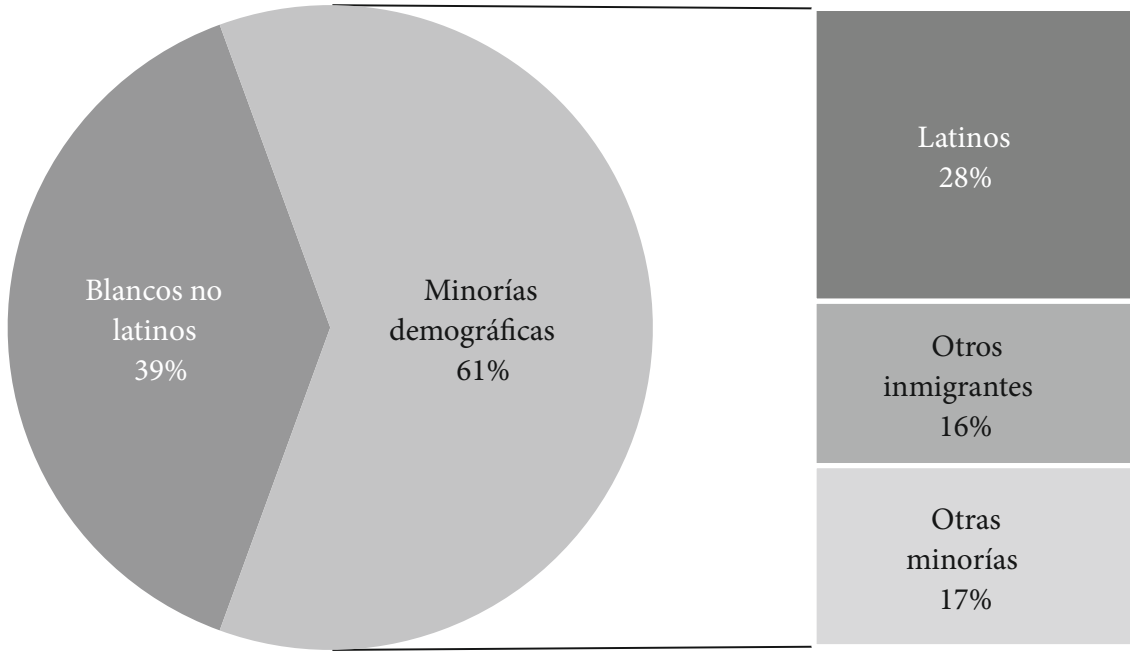

Fuentes: Estimaciones propias con base en BEA, Gross Domestic Product by Industry Accounts, 2000 y 2016; y Current Population Survey, March supplement, 2000 y 2016.

Sin embargo, se trata de una situación no exenta de tensión política. Si en el pasado el sostenimiento de la economía norteamericana como potencia mundial se sustentaba en sus propias fuerzas productivas (mano de obra nativa), hoy en día la demografía de ese país no permite la reproducción de la fuerza de trabajo necesaria para mantener ese nivel de desarrollo de las fuerzas productivas del capital, lo que genera un déficit de mano de obra que de no cubrirse con inmigración no solo afectaría el crecimiento económico de ese país, sino sobre todo su capacidad para mantener el liderazgo político y militar necesario para sustentar sus posiciones hegemónicas a nivel global (Canales, 2015a).

Esto nos permite definir la encrucijada que enfrenta la economía y sociedad norteamericana, y en particular sus élites y clases dominantes. La demografía de su población nativa deviene en obstáculo para mantener su posición hegemónica. La inmigración masiva de mano de obra permite resolver esta contradicción, pero a riesgo de generar una profunda transformación en la composición étnica de la población, lo cual a mediano plazo pone en cuestionamiento la supremacía demográfica de la actual mayoría blanca no hispana. Las consecuencias políticas, sociales y culturales de esta transformación demográfica son impredecibles, pero sin duda apuntan al debilitamiento del poder de las actuales élites y clases que han dominado 
la sociedad y el Estado norteamericano desde su conformación como nación independiente, y a través de él han llegado a una posición de hegemonía política y económica a nivel internacional a lo largo del último siglo de la historia mundial.

\section{Racialización de la desigualdad social y de las ocupaciones}

A pesar de que latinos, migrantes y otras minorías étnicas son el motor del crecimiento demográfico y económico de Estados Unidos, prevalece una estructura de segregación ocupacional y desigualdad social que los margina y excluye de los beneficios del desarrollo (Caicedo, 2010). Por lo pronto, las minorías suelen quedar relegadas a los puestos más bajos de la pirámide ocupacional y a los estratos más bajos de la pirámide social y de ingresos. La desigualdad social adquiere una forma racializada, en donde la posición que cada individuo ocupa en la escala social está directamente determinada por su origen étnico y migratorio (Canales, 2017).

Los datos muestran que en 2017 el $46 \%$ de los trabajadores blancos estaba ocupado en la cima de la pirámide laboral (directivos de empresas y profesionales) y solo el $17 \%$ en la base de la misma (jornaleros y obreros de la construcción y trabajadores en servicios personales de baja calificación, del cuidado, servicio doméstico, limpieza y mantenimiento, y similares). Por el contrario, los latinos muestran una distribución inversa. El $36 \%$ de ellos se empleaba en ocupaciones ubicadas en la base de la pirámide ocupacional, y solo el $23 \%$ en los puestos superiores de la jerarquía laboral. Las otras minorías se ubican en una posición intermedia, aunque más próxima a la estructura de los blancos.

Lo relevante, en todo caso, es que estos datos muestran que mientras que los blancos experimentan una polarización ocupacional hacia arriba, en la que quienes están en la cima de la pirámide laboral casi triplican a los ubicados en la base, en el caso de los latinos se da la relación inversa: predominan los ubicados en los estratos laborales más precarios y vulnerables, los que superan en más de $65 \%$ a los ubicados en el extremo superior de la jerarquía laboral.

Esta diferenciación en la inserción laboral se refleja también en la desigualdad social y de ingresos. Mientras que en el caso de los blancos se da una composición relativamente más equilibrada entre los distintos estratos de ingresos y en ella predomina la población en los estratos medios de ingresos, en los latinos, en cambio, hay una clara concentración en los estratos más bajos. En efecto, el $50 \%$ de los latinos pertenece a los estratos pobres o vulnerables (por debajo de la línea de pobreza o bien con ingresos cercanos a ese nivel), y solo el $14 \%$ se ubica en los estratos medios altos y de altos ingresos (más de 50 mil dólares al año). Las otras minorías reproducen el patrón de los latinos, aunque en forma menos intensa. 
GRÁFICA 9. Estados Unidos, 2017. Estructura ocupacional y estructura de clases (ingresos) según gruposétnicos*

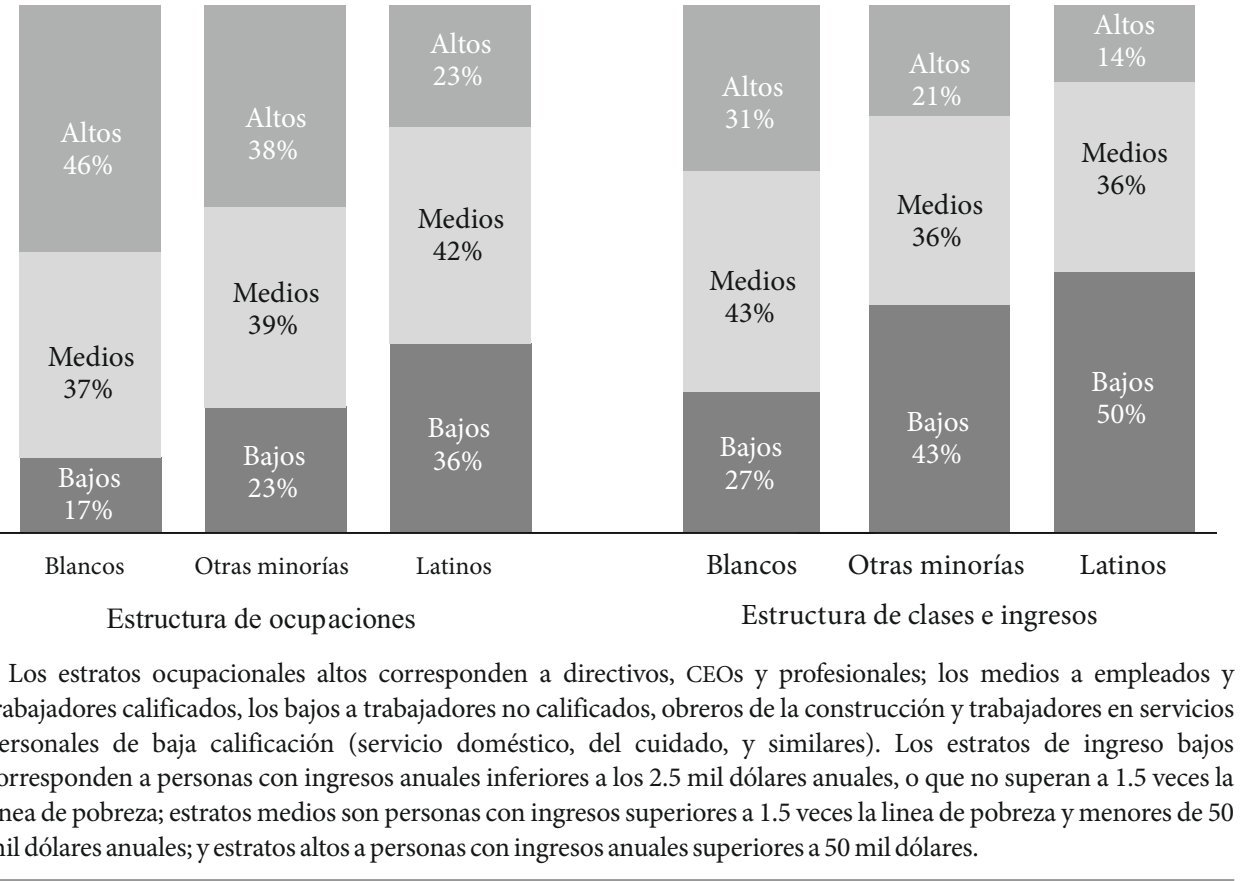

Fuente: Current Population Survey, ASEC, 2017.

Ahora bien, pudiera pensarse que en la medida en que la mayoría blanca se reduzca en volumen y sea remplazada por latinos y otras minorías, esta desigualdad étnica en la inserción laboral y distribución del ingreso debiera reducirse. Esto es, es de esperarse que este remplazo demográfico de blancos por latinos se produzca con pequeñas variaciones en todos los estratos ocupacionales y en todas las clases sociales. Lo cierto es que no parece ser así. Por lo pronto, podemos ejemplificar esto con la situación actual de estados como California, donde el remplazo demográfico de blancos por latinos que ya se ha experimentado no ha modificado sustancialmente la racialización de la desigualdad social y ocupacional. Hoy en día en California, a pesar de que latinos y blancos comparten la primacía demográfica con casi el $40 \%$ de la población cada uno, no comparten sin embargo la misma estructura social y de clases sino que, por el contrario, reproducen la desigualdad racializada que ya hemos comentado.

Tanto respecto a la inserción laboral como a la inserción en estratos socioeconómicos, California prácticamente reproduce vis a vis las estructuras que hemos 
mencionado a nivel nacional. En el primer caso los trabajadores blancos en puestos de dirección y profesionales casi cuadruplican a los que trabajan como jornaleros de la construcción o en servicios personales y de baja calificación. Asimismo, los blancos con más de 50 mil dólares anuales, que a nivel nacional solo superan en cuatro puntos porcentuales a los ubicados en estratos de pobreza o vulnerables, en el caso de California los superan en 10 puntos porcentuales.

En el caso de los latinos resulta impresionante cómo se reproduce prácticamente la misma distribución según categorías ocupacionales y según estratos de ingreso que ya vimos a nivel nacional. Mientras que el $34 \%$ de los trabajadores latinos se emplean en puestos de baja calificación, solo el $20 \%$ logra insertarse en los estratos más altos de la jerarquía ocupacional. Asimismo, en cuanto a su posición en la estructura de ingresos, el $51 \%$ de los latinos residentes en California se ubica en posiciones de alta vulnerabilidad y pobreza de ingresos, mientras que solo el $13 \%$ de ellos pertenece a los estratos de ingresos medios y altos, por sobre los 50 mil dólares de ingresos al año.

GRÁFICA 10. California, 2017. Estructura ocupacional y estructura de clases (ingresos) según grupos étnicos*

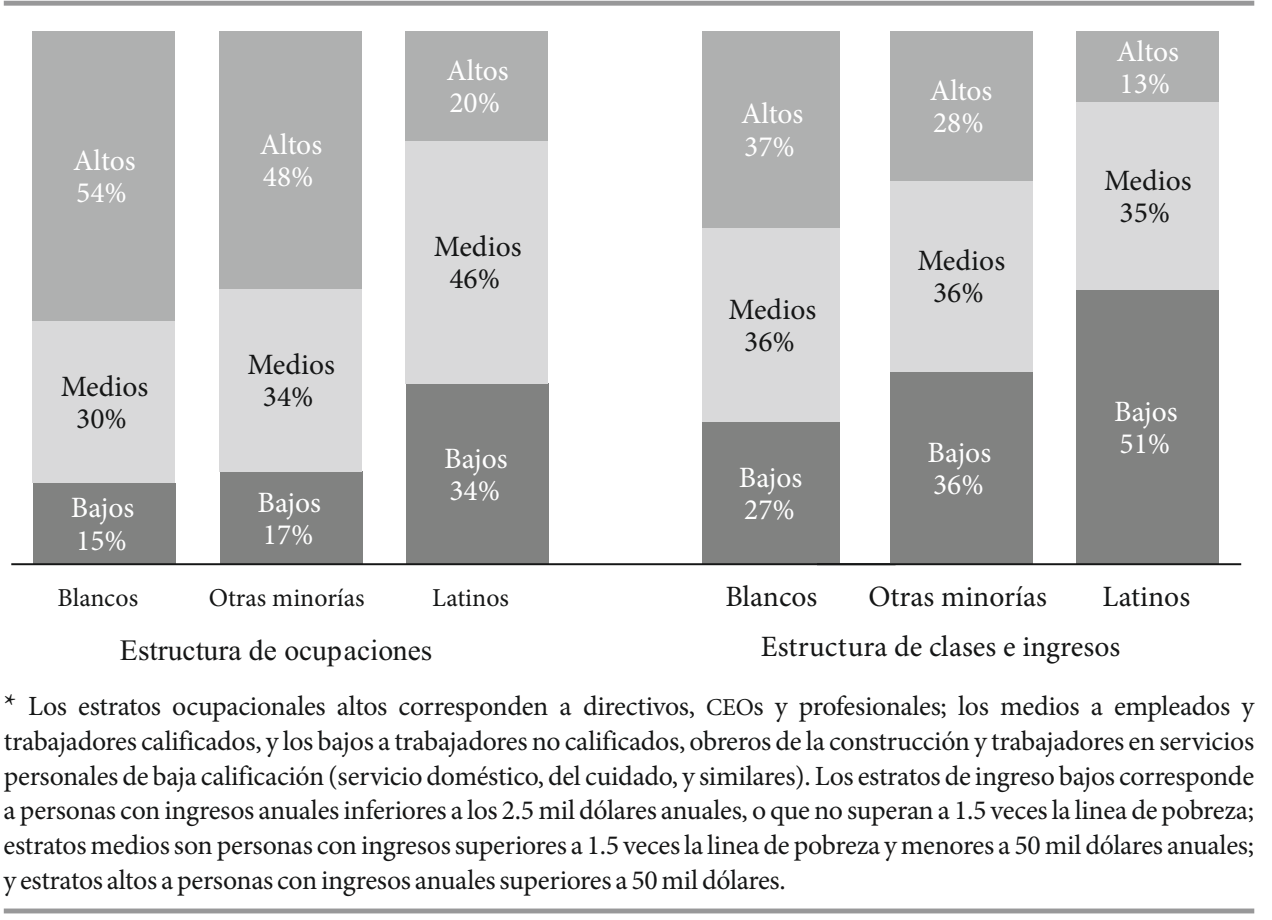

Fuente: Current Population Survey, ASEC 2017. 
Esto es muy relevante, pues nos indica que, aun en un contexto de pérdida de su primacía demográfica, la estructura política y social le ha permitido a la población blanca mantener sus privilegios económicos, e incluso aumentarlos. Por el contrario, en el caso de los latinos, su crecimiento demográfico y el hecho de convertirse hoy por hoy en el grupo étnico más numeroso de California, al menos hasta ahora, no les ha reportado ningún beneficio socioeconómico ni ningún proceso de movilidad social ascendente, visto ya sea desde la perspectiva de las ocupaciones o de los ingresos. Es decir, siguen sufriendo de las mismas carencias y la vulneración de sus derechos sociales y laborales como a nivel nacional.

Sin duda, estamos muy lejos de la configuración de formas de apartheid racial como ocurría en Sudáfrica hasta hace unas décadas. Sin embargo, tampoco es claro que la racialización de la desigualdad pueda ser fácilmente mitigada con procesos de movilidad social intergeneracional, ya sea mediante la educación o por la acumulación de capital social y cultural. Por lo pronto, Telles y Ortiz (2008) señalan, precisamente, que en el caso de la población de origen mexicano la movilidad social intergeneracional es muy débil y no logra romper las estructuras de desigualdad y racialización que la envuelve como grupo étnico en Estados Unidos.

Por otro lado, y siguiendo a Tilly (2000), entendemos que la condición étnicoracial conforma una categoría de desigualdad persistente. Frente a ello, tanto el capital humano como el capital social y cultural, si bien permiten procesos de movilidad social a nivel individual o familiar, no resuelven necesariamente las condiciones de desigualdad categorial que subyace a la situación social de cada sujeto.

\section{Reflexiones finales: polarización ocupacional y racialización de la desigualdad}

Estados Unidos experimenta un ya largo periodo de transformaciones que se refieren a su estructura tanto económica como demográfica. La conjunción de ambos procesos se manifiesta de manera particular en la nueva conformación social y demográfica de la estructura de ocupaciones, en donde, junto con un proceso de polarización del empleo, resurge con fuerza un proceso de racialización de la desigualdad social y la estructura de clases.

En cuanto al cambio demográfico, el ocaso del baby boom de los cincuenta y sesenta, junto con el envejecimiento progresivo y la reducción de los niveles de fecundidad y natalidad de la población blanca, se manifiesta en una dinámica demográfica en que la tradicional pirámide de edades se transforma sustancialmente, pues pasa a tomar la forma de un hongo demográfico, con una base que tiende a 
angostarse frente a una cima que tiende a extenderse y ensancharse. Esta nueva estructura demográfica abre paso a un escenario de desequilibrios en donde la dinámica demográfica nativa ya no está en condiciones de proveer la mano de obra necesaria para mantener los ritmos de crecimiento productivo que requiere y demanda cotidianamente la economía. Se trata de la conformación de un déficit crónico y estructural de mano de obra, el cual ha sido cubierto por inmigración laboral, especialmente proveniente de México y el resto de América Latina.

Paralelamente, el cambio económico enmarcado en la globalización transforma la matriz productiva y ocupacional, lo que deriva en un proceso de polarización del empleo y las ocupaciones. Por un lado, la globalización económica favorece el auge de las ocupaciones de alto nivel, orientadas precisamente a la dirección y organización de la economía de la información, así como a la producción de tecnologías para las demás industrias productivas (Delgado Wise, 2017). Nos referimos al crecimiento del empleo en sectores profesionales, servicios informáticos, servicios a empresas, puestos de dirección, CEOs, ejecutivos financieros, entre muchos otros, todos los cuales dan forma a la industria global del conocimiento en lo que se ha dado en llamar capitalismo cognitivo (Moulier Boutang, 2011). Por otro lado, la misma globalización ha facilitado la relocalización de plantas industriales y de puestos de trabajo hacia economías periféricas (México, América Central, Asia, entre otras), lo que ha derivado en una sustantiva reducción del volumen de los puestos de trabajo directamente productivos que afecta principalmente a los trabajadores manuales, obreros y similares. Por último, los puestos y trabajos dedicados a los servicios de la reproducción social y cotidiana de la población reciben un inusual impulso precisamente a partir del auge de los trabajos de alto nivel. Nos referimos a trabajos como el servicio doméstico y el cuidado de personas, preparación de alimentos, limpieza y mantenimiento de edificios corporativos y de vivienda, servicios de call center y similares de atención estandarizada y masiva de clientes, entre muchos otros. Todos ellos tienen en común ser trabajos de baja calificación, con altos niveles de precariedad y vulnerabilidad, bajos salarios y baja protección legal, pero que resultan cada vez más necesarios para mantener y reproducir la población de los estratos medios y altos que se insertan en los puestos más altos de la jerarquía ocupacional, que la misma globalización ha impulsado.

La combinación de ambas tendencias estructurales abre un nuevo escenario en donde la polarización de las ocupaciones que han documentado diversos autores como consecuencia de la globalización (Castells, 1996; Stiglitz, 2012) deriva en un proceso de racialización de la matriz laboral y ocupacional de Estados Unidos. No se trata solo de un déficit crónico de mano de obra, sino de cómo este déficit adquiere la forma de una demanda y necesidad estructural de un determinado tipo de mano de obra, que pueda insertarse en puestos de trabajo altamente precarios, flexibles y de 
bajos niveles de valoración social y económica, pero que resultan igualmente indispensables para mantener los estilos de vida y patrones de consumo de la población de clases medias y altas, esto es, de quienes se ubican en los niveles altos de la pirámide ocupacional (directivos, gerentes, ingenieros, médicos y otros profesionales, así como técnicos altamente calificados). La reproducción social y cotidiana de estos grupos demanda una continua y creciente mano de obra que la dinámica demográfica local no permite generar. Ante esta situación, la inmigración surge como una respuesta eficaz y eficiente, en términos de que reduce los costos de la reproducción social a la vez que contribuye a mantener y reproducir los beneficios y privilegios de las clases acomodadas.

Asimismo, en un contexto donde la reducción de los trabajos directamente productivos (agrícolas, manufactureros, apoyo administrativo, entre otros) pudiera significar una menor demanda de trabajo no calificado, y por tanto de inmigrantes latinos y mexicanos, el auge de los trabajos en los ámbitos de la reproducción social surge como un nuevo nicho del mercado laboral para estos inmigrantes. La exportación de puestos de trabajo productivos (el llamado off shore) se compensa así con el auge de puestos de trabajo no transables, como lo son los de la construcción y los servicios personales, donde los inmigrantes mexicanos y latinos en general tienden ahora a concentrarse. De esta forma, la demanda de estos trabajos y trabajadores es la contracara de la reconversión económica de la sociedad norteamericana, en donde la nueva matriz laboral y la racialización de las ocupaciones refleja la polarización social y diferenciación étnico-migratoria de la sociedad estadounidense.

No se trata de una situación coyuntural propia de momentos de crisis económica, sino de un proceso estructural que está reconfigurando la estructura de clases de la sociedad norteamericana y en donde la inmigración latinoamericana, y mexicana en particular, participa de un modo fundamental. Esta dinámica de la estructura ocupacional y su racialización son factores estructurales y estructurantes de la reproducción social y económica de la sociedad norteamericana. Las consecuencias, sin embargo, pueden ser muy desestabilizantes. Los nuevos equilibrios demográficos que se avecinan, y que ya se pueden prefigurar en estados como California, Texas y Florida, no parecen ser compatibles con el mantenimiento y la reproducción de formas racializadas de la desigualdad social y la estructura de clases.

Mientras que estas formas de segregación social y étnica afectan solo a una pequeña minoría demográfica, sus contradicciones pueden ser asumidas y absorbidas por el sistema social. Sin embargo, cuando esta segregación racial afecta a una fracción importante de la población (casi el $40 \%$ de ella, como hemos visto en el caso de California), a la vez que mantiene y beneficia a un grupo demográfico igualmente minoritario, la situación se vuelve potencialmente explosiva. En este contexto, retomando a Barba (2011), es posible prever que los dispositivos de cohesión social y 
cultural que prevalecían en el pasado dejarán de tener eficiencia y eficacia para controlar estas nuevas tensiones y contradicciones que esta segregación racial plantea en una sociedad democrática. Es obvio y evidente que cuando los equilibrios demográficos comiencen a modificarse, como se espera que ocurra en las siguientes décadas, esta racialización de la desigualdad social tensará los actuales equilibrios políticos entre los diferentes grupos étnicos y demográficos que componen la población de Estados Unidos, planteando así un escenario con altas dosis de inestabilidad, y que requerirá su transformación por formas más igualitarias y democráticas, lo que pasa por una profunda renegociación y reformulación del pacto social y político sobre el que se constituyó la Unión Americana.

El racismo, como factor de poder social y fáctico que desde su constitución como Estado nacional independiente ha estructurado el sistema de relaciones interétnicas en Estados Unidos, tendrá que ceder a otras formas de relación y estructuración de las clases sociales y de distribución del poder y de los privilegios y beneficios del desarrollo entre los distintos grupos étnicos y demográficos que componen la población norteamericana.

\section{Referencias}

Barba, C. (2011). Revisión teórica del concepto de cohesión social: hacia una perspectiva normativa para América Latina. En Barba, C. \& Cohen, N. (coords.), Perspectivas críticas sobre la cohesión social. Desigualdad y tentativas fallidas de integración social en América Latina (pp. 67-86). Buenos Aires: CLACSO.

Bauman, Z. (2014). ¿La riqueza de unos pocos nos beneficia a todos? Barcelona: Paidós.

Bonilla Silva, E. (2002). 'We are all Americans!: the Latin Americanization of racial stratification in the USA'. Race \& Society, 5, 3-16.

Caicedo, M. (2010). Migración, trabajo y desigualdad. Los inmigrantes latinoamericanos y caribeños en Estados Unidos. México: El Colegio de México.

Camarillo, A. M. \& Bonilla, F. (2001). Hispanics in a multicultural society. A new American dilemma? En Smelser, N., Wilson, W. J., \& Mitchell, F. (eds.), America becoming. Racial trends and their consequences. Washington: US National Academy of Sciences, National Academy Press.

Canales, A. I. (2017). Migración y trabajo en Estados Unidos. Polarización ocupacional y racialización de la desigualdad social en la postcrisis. REMHU, Revista Interdisciplinar da Mobilidade Humana, 25(49), 13-34. Recuperado de: http:// 
www.scielo.br/pdf/remhu/v25n49/1980-8585-REMHU-25-49-013.pdf

Canales, A. I. (2015a). E pur si muove. Elementos para una teoría de las migraciones en el capitalismo global. México: Miguel Ángel Porrúa, Universidad de Guadalajara. Recuperado de https://www.researchgate.net/publication/30867850

Canales, A. I. (2015b). El papel de la migración en el sistema global de reproducción demográfica. Notas de Población, 100, 91-123. Recuperado de http: //repositorio.cepal.org/bitstream/handle/11362/38514/S1500199_es.pdf?sequence $=1$

Castells, M. (1996). The rise of the network society. The information age: economy, society, and culture (vol. I). Cambridge, Mass.: Blackwell Publishers.

Castillo Fernández, D. (2016). La deslocalización del trabajo y la migración hacia Estados Unidos. La paradoja de la “migración de los puestos”. En Castillo, D., Baca, N., \& Todaro, R. (coords.), Trabajo y desigualdades en el mercado laboral (pp. 57-81). México: CLACSO, CEM, UAEM.

Chávez, L. R. (2013). The Latino threat. Constructing immigrants, citizens and the nation. Stanford, Cal.: Stanford University Press.

Coleman, D. (2006). Immigration and ethnic change in low-fertility countries: a third demographic transition. Population and Development Review, 32(3), 401446. Recuperado de http://onlinelibrary.wiley.com/doi/10.1111/j.17284457.2006.00131.x/pdf

Delgado Wise, R. (2017). Claves para descifrar el sistema imperial de innovación comandado por Estados Unidos. Estudios Críticos del Desarrollo, VII(12), 111 139.

Hayes Bautista, D. (2017). La nueva California: Latinos from pioneers to postmillennials (2nd ed.). Oakland, Cal.: University of California Press.

Kesselman, D. (2010). Trabalho precário e precarização institucional nos Estados Unidos. Sociologias, 25, 66-100.

Maldonado, M. M. (2009). 'It is their nature to do menial labour': the racialization of 'Latino/a workers' by agricultural employers. Ethnic and Racial Studies, 32(6), 1017-1036. DOI: 10.1080/01419870902802254

Massey, D. (2015). A missing element in migration theories. Migration Letters, 12(3), 279-299.

Moulier Boutang, Y. (2011). Cognitive capitalism. Cambridge, England: Polity Press. Ortman, J. M., Velkoff, V. A., \& Hogan, H. (2014). An aging nation: the older population in the United States. Population estimates and projections. Washington: U.S. Census Bureau Current Population Reports. Recuperado de https://www.census.gov/prod/2014pubs/p25-1140.pdf

Pickety, T. (2015). El capital en el siglo XXI. México: Fondo de Cultura Económica. 
Stiglitz, J. E. (2012). El precio de la desigualdad. El 1 por ciento de la población tiene lo que el 99 por ciento necesita. México: Editorial Taurus.

Telles, E. \& Ortiz, V. (2008). Generations of exclusion. Mexican Americans, assimilation, and race. New York: Russell Sage Foundation.

Tilly, C. (2000). La desigualdad persistente. Buenos Aires: Manantial.

United Nations (2001). Replacement migration: is it a solution to declining and ageing populations? New York: United Nations.

U.S. Census Bureau (2014). 2014 National population projections. Washington, D.C.: U.S. Census Bureau, Population Division. Recuperado de https://www. census.gov/data/datasets/2014/demo/popproj/2014-popproj.html

U.S. Census Bureau (1975). Historical statistics of the United States, colonial times to 1970 (Bicentennial Edition, Parts 1 and 2). Washington, D.C.: US Census Bureau. 